\title{
Unusual and Unexpected Allergic Reactions Can Be Unraveled by Molecular Allergy Diagnostics
}

\author{
Jon R. Konradsen ${ }^{a, b}$ Magnus P. Borres ${ }^{c, d}$ Caroline Nilsson $^{e, f}$ \\ ${ }^{a}$ Astrid Lindgren Children's Hospital, Karolinska University Hospital, Stockholm, Sweden; 'Department of Women's \\ and Children's Health, Karolinska Institutet, Stockholm, Sweden; 'Department of Women's and Children's

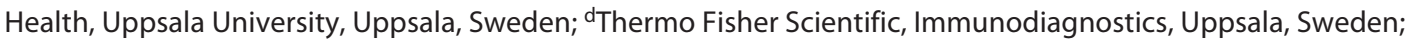 \\ eDepartment of Clinical Science and Education, Södersjukhuset, Karolinska Institutet, Stockholm, Sweden; 'Sach's \\ Children's Hospital, Södersjukhuset, Stockholm, Sweden
}

\section{Keywords \\ Immunoglobulin E - Component-resolved diagnostics . Allergen components · Peanut allergy · Tree-nut allergy · Cashew allergy · Soy allergy · Red meat allergy · Dog allergy $\cdot$ Insect allergy · Cannabis allergy $\cdot$ Crocodile allergy}

\begin{abstract}
The fifth class of immunoglobulin, immunoglobulin E (IgE) was discovered in 1967 and has had immense importance for the understanding, diagnosis, and treatment of allergic disease. More than 50 years have passed and efforts to characterize, standardize, and refine allergens with the aim to improve clinical diagnosis and allergen-specific immunotherapy are still ongoing. Another important breakthrough was made in 1999 with the introduction of component-resolved diagnostics (CRD), making it possible to quantify lgE antibodies against individual allergen proteins for diagnostic purposes at a molecular level. The progress and developments made in allergy diagnosis often originate from clinical observations and case studies. Observant physicians and health-care personnel have reported their findings in the medical literature, which in turn has inspired researchers to become involved in clinical research. Allergists continuously encounter new allergies and are often asked by their pa-
\end{abstract}

karger@karger.com www.karger.com/iaa

Karger $\stackrel{\text { ' }}{5}$
(C) 2021 The Author(s)

Published by S. Karger AG, Basel

This is an Open Access article licensed under the Creative Commons Attribution-NonCommercial-4.0 International License (CC BY-NC) (http://www.karger.com/Services/OpenAccessLicense), applicable to the online version of the article only. Usage and distribution for commercial purposes requires written permission. tients how to prevent new reactions. In the current article, we focus on recent clinical observations that can now be explained by CRD. The examples taken concern allergic reactions toward peanuts, tree nuts, lemon kernels, health drinks, meat, insects, dog dander, cannabis, and semen. We now have an improved understanding of why patients may react in a serious or unexpected way, as illustrated by these examples, yet many other clinical observations remain unexplained. The aim of this review is to highlight the importance of clinical observations among allergic patients, focusing on systemic, or unusual and unexpected allergic reactions, where component-testing has further refined the diagnosis of IgE-mediated allergy.

(c) 2021 The Author(s)

Published by S. Karger AG, Basel

\section{Introduction}

In 1967, the fifth class of immunoglobulin, immunoglobulin E (IgE), was discovered, which has had immense importance for the understanding, diagnosis, and treatment of allergic disease $[1,2]$. More than half a century has passed and efforts are still ongoing to characterize,

Edited by: O. Palomares, Madrid.
Correspondence to:

Jon R. Konradsen, jon.konradsen@ sll.se 
standardize, and refine allergens for improved clinical diagnosis and allergen-specific immunotherapy. The diagnosis of allergy includes having IgE antibodies (IgE-ab) against a specific allergen, in combination with typical allergic symptoms toward the same allergen. If a patient has IgE-ab but no symptoms, the patient is classified as being sensitized. Understanding whether IgE sensitization is a primary (species-specific) event or the result of cross-reactivity to proteins with similar protein structures has been of importance in this work. The molecular quantification of IgE-ab against individual allergen proteins for diagnostic purposes was termed component-resolved diagnosis (CRD) in 1999 [3]. The term molecular allergology describes the science that enables quantification of IgE-ab and IgG-ab against individual allergen proteins [4].

Progress and development in the field of allergy diagnosis often originate from clinical observations and case studies. Observant physicians and health personnel have reported their findings in the medical literature, which in turn has inspired researchers to become involved in clinical research.

In this article, we review recent clinical observations where molecular allergology has been crucial to improving our understanding of unusual and unexpected allergic reactions. The examples are taken concern allergic reactions towards peanuts, tree nuts, lemon kernels, health drinks, meat, insects, dog dander, cannabis, and semen. These reports have been shown to be the starting point in unraveling the mechanisms underlying allergic reactions, and the aim of this review is to describe the usefulness of CRD in these clinical situations. A PubMed search was performed to identify studies on CRD for peanut-, nut-, soy-, dog-, insect-, cannabis, and meat allergies published between 1997 and mid-2020.

\section{From Peanuts to Lemon Kernels}

We know from the nationally representative US surveys (NHANES) that the consumption of nuts and seeds increased significantly between 1999 and 2012 [5]. As there is a dose-dependent relationship between the frequency of nut consumption and the frequency of sensitization [6], we foresee an increase in allergies toward nuts and seeds in the future.

\section{Peanut and Hazelnut}

Many patients sensitized to peanut do not develop any, or show only very mild symptoms upon exposure to pea-

Highlighting the Usefulness of Molecular

Allergy in Clinical Practice nut, whereas others can develop systemic and sometimes life-threatening reactions. Molecular allergology has made it possible to identify which patients will develop systemic reactions, and several worldwide studies give consistent results; IgE-ab against the $2 \mathrm{~S}$ albumin storage protein, Ara h 2, in peanut shows the highest diagnostic accuracy for peanut allergy leading to systemic allergic reactions. A recent systematic review of pediatric studies from 2019 shows that IgE-ab against Ara $\mathrm{h} 2$ with a cutoff of $0.35 \mathrm{kU} / \mathrm{L}$ has a sensitivity of $85.8 \%$ (95\% CI 79.3-90.6) and a specificity of $83.6 \%$ (95\% CI 76.0-89.2) [7]. Recently, Tedner et al. [8] also showed that even infants at 3 months of age are able to produce an IgE response to Ara h 2.

A similar pattern is observed for hazelnut; many patients sensitized to hazelnut do not develop any or only very mild oral symptoms upon exposure to hazelnut, whereas other patients can develop systemic and sometimes life-threatening reactions [9]. In birch endemic areas, up to $84 \%$ of those sensitized to birch are also sensitized to hazelnut [10], and therefore, analyzing IgE-ab to hazelnut extract, which has a low diagnostic specificity for systemic allergic reaction to hazelnut, can lead to overdiagnosis [11]. Analysis of the hazelnut allergen molecules, Cor a 9 (11S globulin) and Cor a 14 (2S albumin), has enhanced the diagnostic precision of hazelnut allergy, and most importantly, has revealed that many individuals who thought they had severe allergy toward hazelnuts are in fact healthy [11]. However, there have been discrepancies concerning the diagnostic capacity of these molecules across all ages; Cor a 9 and Cor a 14 seem to be good predictors of hazelnut allergy in children [11] but are not as convincing in adults [12]. A systematic review shows that IgE-ab to Cor a 14 has the best precision in diagnosing systemic allergic reactions in response to oral hazelnut challenge, open or blinded, in children with a sensitivity of $78 \%$ (95\% CI $71-83)$ and a specificity of $82 \%$ (95\% CI 77-86) using a cutoff of $0.35 \mathrm{kU} / \mathrm{L}$ [11].

\section{Walnut and Pecan}

Walnut is the most prevalent nut allergy reported in the US [13], but it has been shown that $20 \%$ of patients have asymptomatic sensitization [14]. Walnut, as all other plant-based foods, cross-reacts serologically with pollen, and sensitization to walnut can occur as a result of birch pollen sensitization or sensitization to other nuts [15]. In the NUT CRACKER study, it was shown that identification of IgE-ab against certain walnut allergen components (storage proteins) can be helpful in distinguishing allergy from sensitization [14]. Sato et al. [16] 


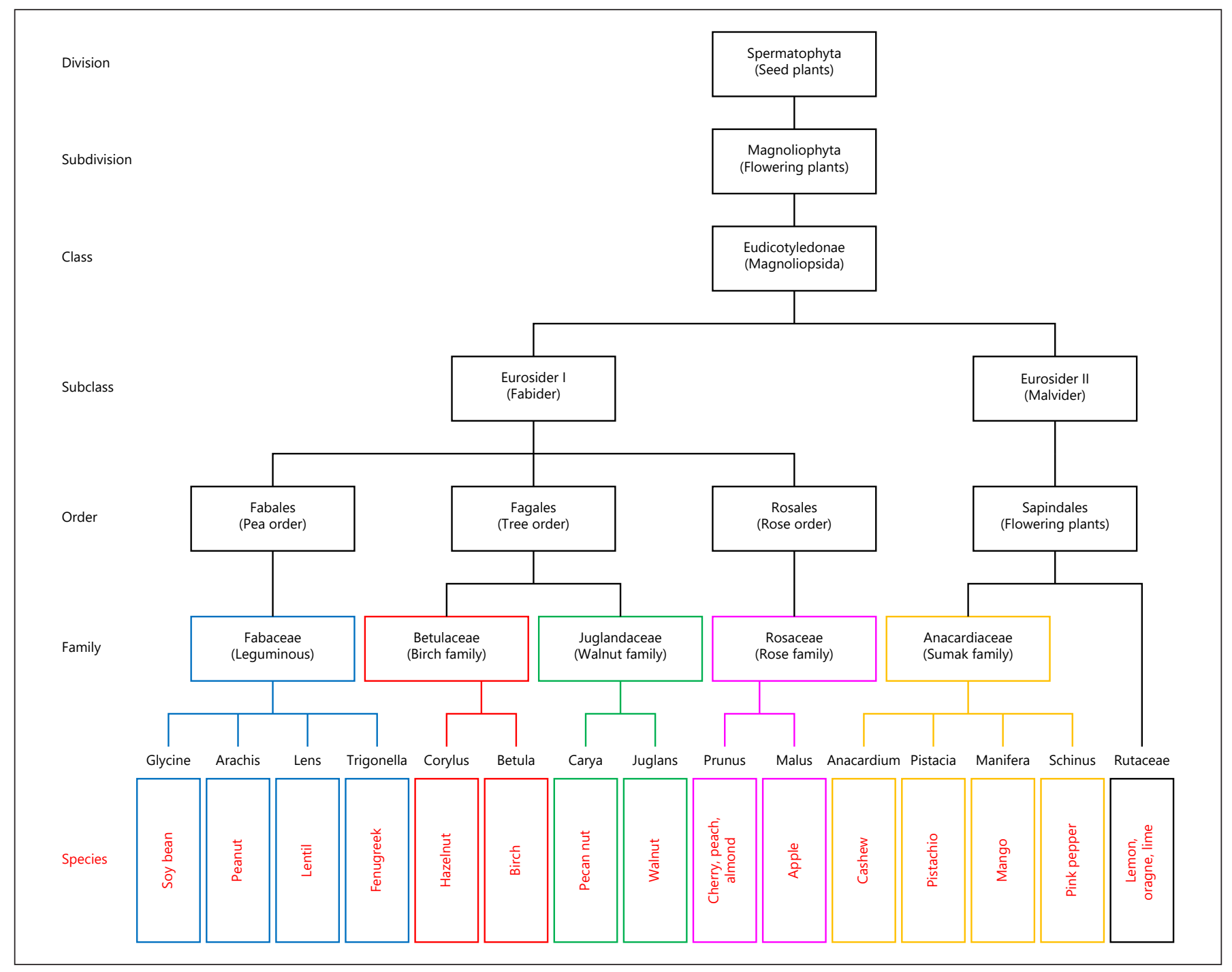

Fig. 1. Botanical relationship showing the relations between different species. This classification does not include all botanical classifications.

have shown that the specificity for diagnosing walnut allergy using Jug $\mathrm{r} 1$ ( $2 \mathrm{~S}$ albumin) with a cutoff of $0.35 \mathrm{kU} / \mathrm{L}$ is around 75\%, whereas in the NUT CRACKER study [14] specificity reached $82 \%$ when compared with a walnut challenge in patients with Jug $\mathrm{r} 1 \mathrm{IgE}>0.35 \mathrm{kU} / \mathrm{L}$. Furthermore, in patients with $\operatorname{IgE}>0.35 \mathrm{kU} / \mathrm{L}$ for both Jug $\mathrm{r} 1$ and Jug $\mathrm{r}$ 4, diagnostic accuracy was improved to 93\% [14].

Pecan allergy is associated with walnut allergy as these nuts originate from the same botanic family, Juglandaceae, Figure 1 . In the NUT CRACKER study, $80 \%$ of individuals with walnut allergy also reacted to pecan, and all individuals that reacted to pecan were allergic to wal- nut. The presence of IgE against Jug r 4 seemed to be a good marker for dual allergy toward walnut and pecan [14].

\section{Cashew and Pistachio}

In a multicenter European study on anaphylaxis, cashew nut was the sixth most common single food allergen [17]. We performed a 10-year review of trends concerning the severity of allergic reactions toward nuts and other foods in Sweden. The only food reactions that increased during the study period were reactions caused by cashew [18]. In a population-based case study, Vetander et al. [19] studied anaphylaxis and other allergic reactions in 
Table 1. Description of the 4 cases

\begin{tabular}{lllll}
\hline & Patients & & & \\
\cline { 2 - 5 } & case 1 & case 2 & case 3 & case 4 \\
\hline Gender & $\mathrm{M}$ & $\mathrm{F}$ & $\mathrm{M}$ \\
Age, years & 17 & 16 & 6 & 2 \\
Food causing reaction & Drink with lemon juice & Lemon seed & Tangerine seed & Fish with lemon dressing \\
Clinical symptoms & Anaphylaxis & Local edema, itching & Local edema, itching & Urticaria, itching \\
Prick-to-prick test & Lemon & Lemon & Tangerine & Lemon \\
Lemon/tangerine seed, mm & 9.5 & 3 & 10 & 3.5 \\
SPT positive control (histamine), mm & 5 & 10 & 5 & 5 \\
\hline IgE analyses, $k U / L$ & & & \\
Cashew & 8.3 & & 12.8 & 3.6 \\
Ana o 3 & 16 & 7.3 & 4.1 & 1.2 \\
Orange seed & 15 & 10 & 2.3 & 3.0 \\
Lemon seed & 6 & 8.0 & 4.5 & 2.4 \\
Lemon 2S albumin & 13 & 3.6 & 0.6 & 0.6 \\
Lemon 7S globulin & 1.2 & 7.6 & 1.0 & 0.7 \\
Lemon 11S globulin & 1.8 & 0.3 & 0.0 & 1.9 \\
Orange & 0.2 & 0.8 & 0.8 & 0.5 \\
Lemon & 2.0 & 0.1 & 0 & 0.9 \\
Pru p 3 (LTP) & 0.2 & 1.2 & 0 & 4.6 \\
\hline
\end{tabular}

Reprinted from Brandstrom et al. [28] with permission. The 4 cases were all allergic to cashew and had reactions to citrus seeds (cases 2 and 3 ) or foods contaminated with citrus seeds (cases 1 and 4). Apart from their reactions to citrus fruits described, they have all been eating citrus fruits including lemon, both before and after their reactions, without developing any allergic symptoms and were thus considered tolerant to citrus fruit pulp. IgE, immunoglobulin E.

children attending pediatric emergency departments. They found that peanuts and tree nuts, particularly cashew, were the most common foods eliciting a reaction, and in children under 3 years of age, reactions to these 2 food allergens were as common as those toward milk and egg.

Cashew belongs to the Anacardiaceae family along with pistachio, pink peppercorn, mango, and sumac, a Middle Eastern herb, Figure 1. A high degree of clinical cross-reactivity is known towards pistachio [20-22], but not mango, probably because the mango kernel is not eaten. The prevalence of pink peppercorn allergy is currently unknown, but sensitization to pink pepper among those with a cashew nut allergy seems to be $76 \%$ [23].

Ana o 3 is the stable storage protein, $2 \mathrm{~S}$ albumin of cashew, and is highly predictive of cashew allergy in children [22] at a low IgE-ab cutoff [20, 22]. In Greek children, the sensitivity and specificity were 98 and $94 \%$, respectively, using a cutoff of $0.16 \mathrm{kUA} / \mathrm{L}$ [22]. Furthermore, Blazowski et al. [24] showed that IgE-mono-sensitization to Ana o 3 is associated with a high risk of severe anaphylaxis. This cashew allergen (Ana o 3) can be used as a specific marker of pistachio allergy as well, since immunologically, cashew and pistachio appear nearly iden- tical [21]. Andorf et al. [25] have both been able to show serological cross-reactivity between cashew and pistachio, as well as clinical cross-reactivity as verified by DBPCFC. All children with pistachio allergy reacted to challenges with cashew, and 42 out of 46 children with cashew allergy reacted when challenged with pistachio. It may, therefore, be especially important for physicians to advise strict avoidance of both Anacardiaceae members if a patient reacts to either of these two nuts. It may also be of importance to inform individuals with a cashew/pistachio allergy to be careful with pink peppercorn and mango kernels.

\section{Lemon Kernels}

A number of clinical observations and reports have been published over the past decade regarding individuals with a cashew nut allergy also displaying reactions to citrus seeds [26-28], Table 1 [28]. The Rutaceae family (e.g., lemon, tangerine, or orange) is botanically closely related to the Anacardiaceae family, to which cashew and pistachio belong, Figure 1. Some patients with a cashew allergy can react systemically when they are exposed to these kernels. For this situation, molecular allergology can be helpful in explaining the clinical observations. The 
Table 2. Reprinted with permission from [31]

\begin{tabular}{|c|c|c|c|c|c|c|c|c|c|}
\hline patient & age, years & sex & $\begin{array}{l}\text { Reaction to soy drink } \\
\text { symptoms }\end{array}$ & birch & soybean & Bet v 1 & Gly m 4 & Gly m 5 & Gly m 6 \\
\hline 2 & 14 & $\mathrm{~F}$ & dy, git, s, e & 99.6 & 0.5 & 81.8 & 40.9 & 0.0 & 0.0 \\
\hline 3 & 10 & $\mathrm{~F}$ & dy, s, n, e & 63.2 & 0.2 & 59.7 & 10.8 & 0.0 & 0.0 \\
\hline 4 & 10 & M & dy, s, thi & 74.9 & 0.0 & 61.9 & 10.5 & 0.0 & 0.0 \\
\hline
\end{tabular}

Four children from Sundsvall, Sweden, were identified after they experienced severe symptoms shortly after the ingestion of flavored soymilk drink at the peak of the birch pollen season. Two were admitted to emergency care, and 2 consulted their allergy specialist after the episode. All had birch pollen allergy and related oral allergy syndrome from fruits and/or vegetables, and none had reacted to soy protein previously. All had a normal diet containing soy but had not been exposed to soymilk before. They had not been exercising at the time of the reaction, and they were not infected according to the case report. dy, dyspnea; co, cough; thi, tightness of throat; git, gastrointestinal pain; s, swelling of lips; e, emesis; n, nausea; IgE, immunoglobulin E. * Not done due to shortage of sample.

storage proteins, $11 \mathrm{~S}$ globulin, $7 \mathrm{~S}$ globulin, and $2 \mathrm{~S}$ albumin, have now been isolated from lemon seeds and described as allergens [28]. However, while serological cross-reactions between homologous proteins from cashew and citrus seeds have been described, these need to be further documented.

It is important to consider the risk of systemic allergic reactions in cashew allergic individuals who come in contact with cross-reacting allergens from other foods. Physicians should be aware of the potential for co-sensitization to cashew and citrus seeds, especially in light of the increasing prevalence of cashew allergies. Patients allergic to cashew should be informed that chewing citrus seeds can trigger an allergic reaction. Furthermore, freshly squeezed juice can contain seeds that may be crushed during preparation. Studies have shown that there is complete IgE-ab cross-reactivity between lemon, mandarin, and orange seeds, and it is, therefore, necessary to avoid all 3 types of seed. Allergies to fruit seeds are probably under-recognized, and physicians should consider fruit seeds to be a potential cause of apparent idiopathic anaphylaxis in patients with nut allergies [29]. However, the pulp of citrus fruits can still be eaten, even if a patient is allergic to cashew or pistachio.

\section{Health Drinks and Soy Reactions}

Over the past decade, it has been reported that a number of patients allergic to birch pollen develop severe reactions upon their first exposure to soy drinks [30, 31]. Van Zuuren et al. [30] describe 6 adult patients who developed a swollen tongue, angioedema, urticaria, rhino- conjunctivitis, and/or hypotension within 15-30 min of soy milk consumption and were treated for their anaphylaxis at the emergency department. Kosma et al. [31] report that 4 children experienced severe symptoms shortly after the ingestion of soy milk, all in the same city during the peak of the birch pollen season, Table 2. Their mothers had received soy milk formula as a sponsored gift during a fundraising event and gave it to their children with birch allergy. The severe reactions came as a surprise to all 4 families as their children had not been considered to have a soybean allergy.

Soybean causes food allergy in childhood, especially in Asia. Children with soybean allergy usually develop tolerance, and prevalence of a true soybean allergy is, therefore, rare among adults. In addition, an allergy toward soybean can also be caused by IgE-ab cross-reactivity for Bet $\mathrm{v}$ 1, the major allergen of birch pollen and its homologue; pathogenesis-related class 10 protein (PR-10) in soybean, Gly $\mathrm{m}$ 4. This type of cross-reaction between birch and soybeans involves a different IgE-component pattern compared to true soybean allergy, where an $\operatorname{IgE}$ response to the storage proteins, $7 \mathrm{~S}$ globulin (Gly $\mathrm{m} \mathrm{5}$ ) and $11 \mathrm{~S}$ glycine (Gly $\mathrm{m}$ 6), is present [4].

It is a common belief that patients with pollen-related food allergies have mild oropharyngeal symptoms, which is not true for soybean. Kleine-Tebbe et al. [32] suggested an association between birch and soybean allergy for the first time in 2002. Approximately 50\% of patients with birch and soy allergy experienced systemic and even anaphylactic reactions after soy consumption [33]. Mittag et al. [33] estimate that $10 \%$ of patients who are highly sensitized to birch pollen also have a soybean allergy. 
Japan constitutes one of the largest soybean-consuming populations in the world. Fukutomi et al. [34] used CRD to characterize a group of adult patients in Japan $(n=21)$, with a known allergy toward soybean in order to investigate occurrence of the 2 forms of soybean allergy. Surprisingly, all patients were sensitized to Gly $\mathrm{m} 4$, and the most common symptoms were oral allergy syndrome, cough/dyspnea, and abdominal pain/diarrhea after intake of soybeans. Alder is part of the Betulaceae family, and its pollen is of minor clinical importance in terms of respiratory allergies, but alder sensitization seems to be of high impact on the development of adult soybean allergy. Alder sensitization seems to be the explanation for why many Japanese patients with a pollen allergy experience Gly $\mathrm{m} 4$ reactions to soy.

Mittag et al. [33] measured the content of Gly m 4 in commercially available soy foods to determine the stability of this allergen in relation to different food-processing methods. The highest amounts of Gly $\mathrm{m} 4$ were measured in soy drinks, whereas no Gly $\mathrm{m} 4$ was detected in fermented products, such as soy sauce and miso. Heating denatures the allergen and destroys the antibody-binding capacity of Gly $\mathrm{m} 4$ as no protein was found in roasted soybeans or in soybeans cooked for $4 \mathrm{~h}$.

A growing number of individuals in our society avoid dairy products for medical reasons or as a lifestyle choice [35]. Medical reasons include lactose malabsorption, with a worldwide prevalence of $68 \%$ in adults [36], and allergy toward cow's milk. The most widely consumed plant milk substitute in the western world is soy milk, followed by coconut, oat, and almond [37]. With this in mind, we foresee an increase in the number of similar cases of pollen-related soybean reactions when the consumption of plant substitutes increases due to prevailing health trends. Physicians and patients with birch pollen allergies should be aware of the risk of consuming soy milk, especially during the birch pollen season.

\section{Novel Clinical Manifestations of Pollen Allergy}

An interesting link between birch pollen allergy and irritable bowel syndrome (IBS) has recently been described by Patel et al. [38]. Individuals with IBS were found to have a high incidence of seasonal allergic rhinitis and consequent pollen-food syndrome (PFS). The patients displayed increased IBS severity if they had seasonal allergic rhinitis as a comorbidity. This clinical observation is supported by Rentzos et al. [39] who performed duodenal biopsies in IBS patients. They observed exacer-

Highlighting the Usefulness of Molecular Allergy in Clinical Practice bations or an onset of IBS symptoms and increased numbers of inflammatory cells in the duodenal mucosa during the birch pollen season in individuals with birch pollen allergy. Another recent description of the severe implications of PFS concerns Gibberellin-regulated protein allergy $[40,41]$. These proteins are found in peach (Pru $\mathrm{p}$ 7) and cypress pollen among others. Sensitization to Pru p 7 and allergenic homologues of the Gibberellin-regulated protein-family occurs in areas with high exposure to Cupressaceae tree pollen. Studies from southern Europe and Japan document that this form of PFS is severe involving frequent systemic reactions with laryngeal tightness and facial swelling, especially eyelid edema. These severe PFS reactions have not previously been described, and IgE-ab measurements of Pru p 7 seem to predict the severity of the food reaction.

An increasing number of studies have recently demonstrated that PFSs occur in all age-groups and that a significant number of affected adults experience systemic and anaphylactic reactions [42]. These could be exacerbated by the upsurge in vegan lifestyles, increased consumption of fruits and vegetables, including smoothies and juices, and use of plant foods in nutritional or bodybuilding supplements. Accordingly, all individuals with PFS should be properly advised regarding the dangers of concentrated or unusual forms of plant food allergens such as smoothies, juices, soy/nut milks, and nutritional supplements.

\section{Allergy to Meat from Mammals and Archosaurs}

Allergy to meat does exist and can help interpret previously unexplained allergic reactions. It is now possible to measure IgE-abs against different proteins originating from meat in mammals, and partly from animals originating from the archosaur clade (crocodilians and birds). Three types of mammalian meat allergy are described, primary allergy to beef, "pork-cat syndrome," and alphagal syndrome (AGS).

\section{Primary Beef Allergy}

Primary beef allergy, where symptoms usually start within an hour after consuming beef, has mainly been described in atopic infants but in rare cases also occurs in adults. The majority of these children grow out of their meat allergy in primary school. The allergic symptoms can be mild to severe, and individuals may experience itching in the mouth and throat, urticaria, gastrointestinal symptoms, and/or anaphylaxis. The most well-char- 
acterized allergen in primary beef allergy is bovine serum albumin (Bos d 6, a major allergen), but bovine immunoglobulin (Bos d 7), has also been identified [43]. Bos d 6 is found in muscle and milk, which explains why many patients with a primary allergy to beef also have reactions when consuming milk. In a study of 28 children with primary beef allergy, $93 \%(n=26)$ were also allergic to milk [44]. On the other hand, when investigating children with milk allergy, $13-20 \%$ also reported a meat allergy [45].

\section{"Pork-Cat" Syndrome}

Individuals who are allergic to cats may develop IgE against cat albumin, Fel d 2 (serum albumin), and individuals sensitized to Fel d 2 may develop allergic symptoms in conjunction with the consumption of pork. This is due to the IgE cross-reaction between Fel $\mathrm{d} 2$ and porcine (bovine) albumin, Sus s $1[43,44]$. Occasionally, there is also a cross-reaction between Fel d 2 and bovine albumin, Bos d 6, in which case allergic symptoms occur after the consumption of beef. Those affected are usually adolescents or young adults, and the majority of individuals with "pork-cat" syndrome are, or have been, cat owners. Symptoms usually start within an hour after eating pork and can be mild to severe, with individuals experiencing itching in the mouth and throat, urticaria, gastrointestinal symptoms, and/or anaphylaxis $[43,44]$.

\section{Alpha-Gal Syndrome}

Some patients develop delayed allergic symptoms, usually $2-7 \mathrm{~h}$ after consuming mammalian meat or intestinal food. The majority of these individuals have urticaria and gastrointestinal symptoms, and almost half experience anaphylaxis. As a rule, patients do not get symptoms every time they eat mammalian meat or intestinal food [46]. Reactions can also be triggered by blood, dairy products, and gelatin from mammals, but these reactions are usually milder than those triggered by mammalian meat [47]. This allergy to mammalian meat is often caused by IgE-ab against the carbohydrate galactose-alpha-1,3galactose (alpha-gal), a carbohydrate found in glycolipids and glycoproteins in mammals, but absent in humans and higher primates [48]. Alpha-gal is also found in ticks (Ixodes), both in saliva and the gastrointestinal tract. Tick bites can lead to sensitization toward alpha-gal and the development of alpha-gal syndrome (AGS), that is, allergic symptoms upon exposure to red meat caused by IgE$\mathrm{ab}$ against alpha-gal. The majority of individuals with AGS tolerate the consumption of dairy products in limited quantities. Interacting factors such as alcohol, physi- cal exertion, and ASA/NSAIDs may increase the tendency of an individual to react. Alpha-gal is heat stable, and reactions can occur even after consuming well-cooked meat. Allergy usually develops in adulthood but also occurs in children. The presence of IgE-ab against alpha-gal can occur in the absence of allergic symptoms, which is why clinical history is of particular importance. In AGS, the level of IgE-ab against alpha-gal is usually higher than $\operatorname{IgE}-\mathrm{ab}$ against beef and pork. IgE against a number of mammalian proteins (e.g., cat, dog, milk, and gelatin) may be detectable in this allergy as alpha-gal is also found in these allergen sources [43]. It has recently been shown that AGS patients with IgE against the milk protein lactoferrin have a higher risk of anaphylaxis than those who do not [49]. The observed IgE reactivity against lactoferrin is likely due to the $\alpha-G a l$ present in lactoferrin. It is worth keeping in mind that newly discovered, elevated levels of IgE-ab against milk in adults may be due to alpha-gal allergy.

\section{Allergy to Archosaur (Poultry and Crocodile) Meat}

The most common bird meat eaten in society is chicken, followed by hen and turkey, which are considered hypoallergenic foods. Reliable prevalence data is missing, but allergy toward these poultry seems to be uncommon. Nevertheless, allergy to poultry can cause severe allergic reactions in both children and adults [50]. Knowledge regarding allergenic components and their significance in relation to cases of poultry meat allergy is limited, and at present, there are no components available for poultry meat. Among the poultries, chicken is the most frequently reported allergen to trigger an allergic reaction, and individuals allergic to chicken meat are usually also allergic to turkey meat [50]. Furthermore, there is also crossreactivity with other poultry meat, such as duck and goose. Components that have been shown to be important in chicken allergy (chicken parvalbumin, aldolase, and enolase) are currently only used for research purposes [51].

Crocodile meat is rarely eaten in Europe, but a relationship between bird and crocodile exists biologically, as both originate from the archosaurs [52]. At the protein level, there is also a similarity between crocodile parvalbumin and chicken parvalbumin, and accordingly, individuals allergic to chicken may react to crocodile meat. There is one case report of a 13-year-old boy with a confirmed allergy to poultry, especially chicken, who experienced anaphylaxis when eating crocodile meat [51]. As mentioned, the protein structure of crocodile parvalbumin and chicken parvalbumin has been shown to be very 


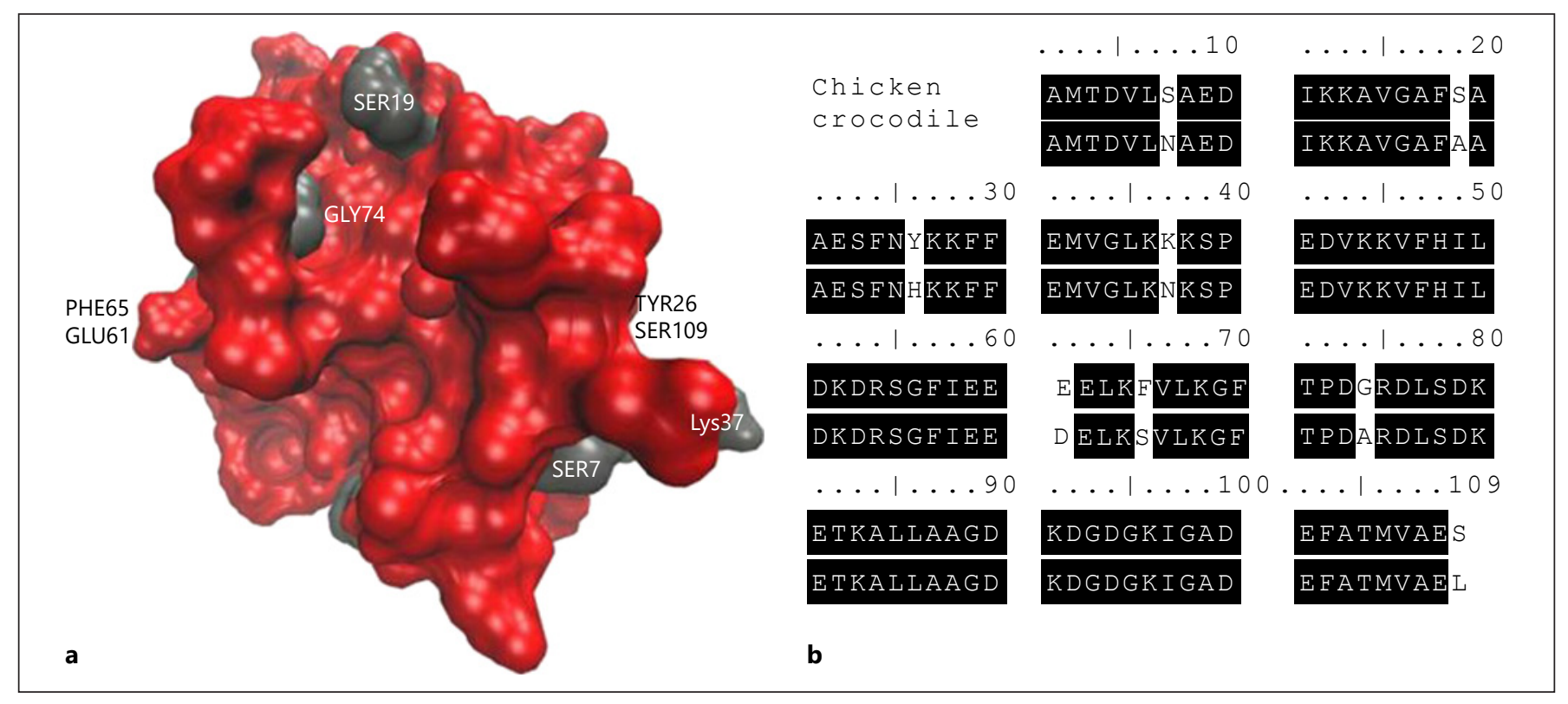

Fig. 2. Reprinted from [51] with permission. Comparison of chicken and crocodile a-parvalbumin. a Three-dimensional model of chicken parvalbumin, protein surface coloring by identity to crocodile parvalbumin. Red, identical residues; gray, variable residues. b Amino acid sequence alignment of chicken and crocodile parvalbumins as allergens involved in the clinical cross-reaction to both meats.

similar, Figure 2 [51]. The protein identity of the $14-\mathrm{kDa}$ crocodile parvalbumin compared with the chicken homolog was $94 \%$. One may, therefore, speculate that individuals allergic to poultry should be careful eating crocodile meat.

Another possible cross-reaction with poultry is fish, where Cod parvalbumin and Carp parvalbumin, the main allergens in fish allergy can cross-react with chicken parvalbumin [53]. Allergists have heard patients with fish allergy complaining of allergic reactions toward chicken meat and have tried to explain this cross-reaction by assuming the chicken had probably had eaten fish-based food. However, individuals who are allergic to chicken may in fact also react allergically to fish and vice versa, due to the cross-reaction between parvalbumin in chicken and fish [53].

\section{Insects as a New Food - Is There a Risk for Allergic Reactions?}

There is a need for new sustainable foods due to the growing world population and new environmental challenges. Mounting evidence suggests that the production of insects for human consumption will help meet these needs/challenges. However, there is limited knowledge regarding food safety issues, where allergies are one concern. Insects are already part of the human diet worldwide, with the exception of Europe and parts of North America. Europe is, however, the fastest-growing market in the global edible insect industry, and the market is expected to register a compound annual growth rate of $7.3 \%$ (in terms of revenue) until 2024 [54]. Entomophagy (the human consumption of insects) is about to become established in Europe, and in the Netherlands, Denmark, and Finland, there are already products for sale. Since October 2020, it has been permitted to sell whole insects as food (Regulation No. 258/97 of the European Parliament and of the Council concerning novel foods and novel food ingredients, foods consisting of whole animals intended to be consumed as such, including whole insects).

It has recently been shown that patients with shrimp allergy are at risk of secondary allergy toward mealworms and crickets, most likely resulting from cross-reactions to the muscle protein tropomyosin $[55,56]$. Tropomyosin is not only expressed in shrimp, but homologous forms are also found in mollusks, insects, and arachnids. Therefore, we believe that patients with primary allergies toward shrimp and house dust mites might be at risk of crossreactions toward insects although supporting observations are still lacking. Preliminary data from a Swedish adult population study show sensitization rates of $6 \%$ to 


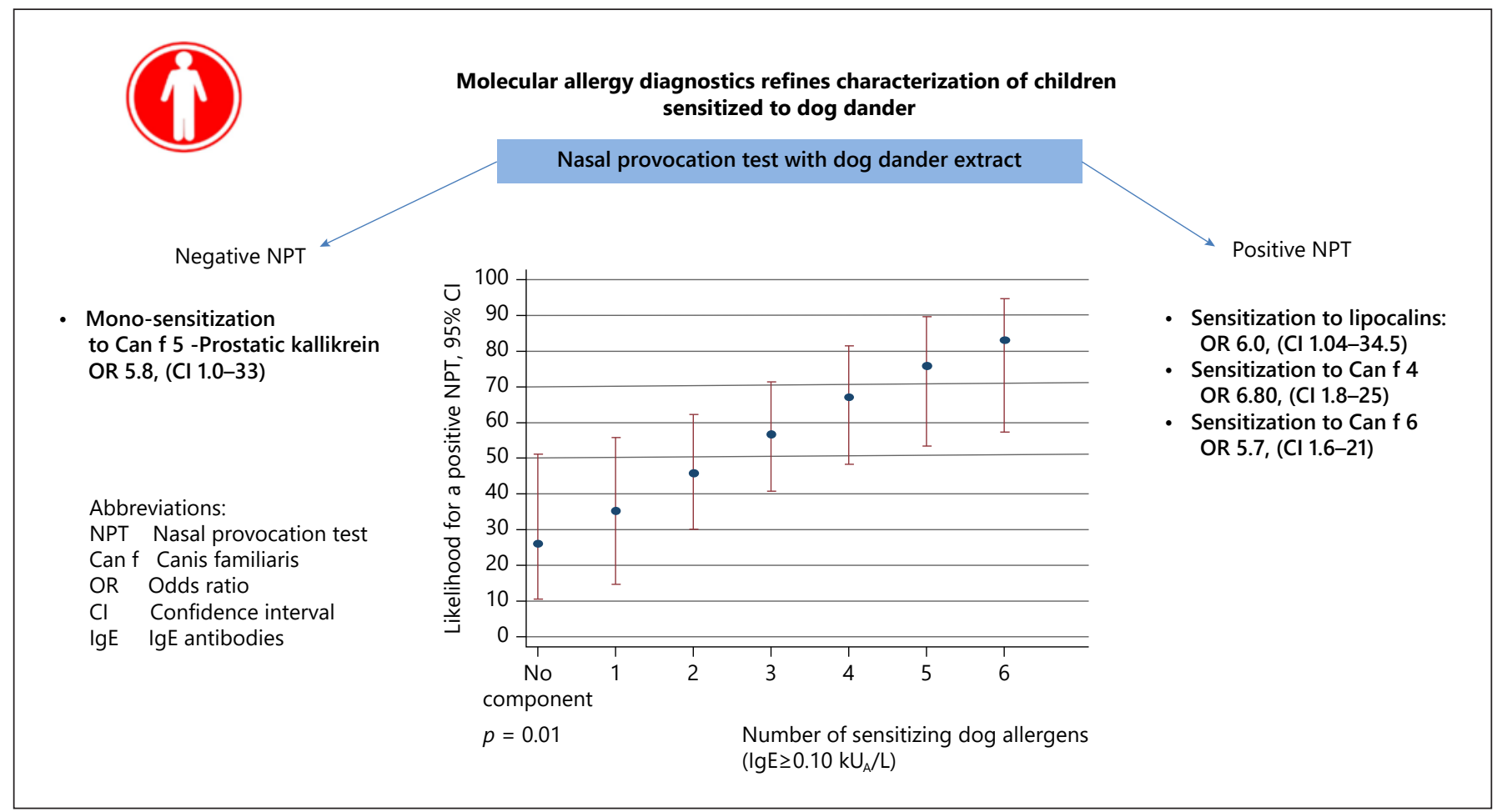

Fig. 3. Reprinted with permission from [67]. Sixty children (age, 10-18 years) sensitized to dog-dander extract underwent NPTs with dog-dander extract. Measurement of IgE levels to dog dander and Can f 1, Can f 2, Can f 3, and Can $\mathrm{f} 5$ was performed with ImmunoCAP, and measurement of IgE levels to Can $\mathrm{f} 4$ and Can $\mathrm{f} 6$ was performed with streptavidin ImmunoCAP. An IgE level of 0.1 $\mathrm{kU}_{\mathrm{A}} / \mathrm{L}$ or greater was considered positive. Results: there was an association between sensitization to an increasing number of dog allergen components and a positive nasal challenge result. Sensitization to lipocalins (OR, 6.0; 95\% CI, 1.04-34.5), in particular, Can f 4 (OR, 6.80; 95\% CI 1.84-25.2) and Can f 6 (OR, 5.69; 95\% CI, 1.59-20.8) were associated with a positive NPT result. Mono-sensitization to Can $\mathrm{f} 5$ was related to a negative NPT result (OR, 5.78; 95\% CI, 1.01-33.0). IgE, immunoglobulin E; OR, odds ratio; NPT, nasal provocation test.

of these new, or modified proteins, is crucial to ensure protection of public health. Exposure to new proteins may result in de novo sensitization, with or without clinical allergy, or clinical reactions as a result of cross-reactivity. With the increasing interest in edible insects, there is an urgent need for improved knowledge concerning these issues.

\section{Allergy to Male, but Not Female, Dogs}

For individuals sensitized to dog, exposure to dog dander is an important cause of allergic airway symptoms yet an interesting clinical observation is that some dog-allergic patients only develop symptoms upon exposure to male dogs [60]. In total, 8 different dog allergens have been identified and characterized, Can $\mathrm{f} 1$ to Can $\mathrm{f} 8$ [6163]. Prostatic kallikrein, Can $f 5$, is expressed in the pros- 
tate and has been detected in the urine of male dogs, as well as extracts of hair and dander [64]. Even in 2009, when this protein was first identified as a major dog allergen, it was speculated that exposure to neutered or female dogs could be tolerated in mono-sensitized individuals, as these dogs do not produce Can $\mathrm{f} 5$ [64]. Sensitization to Can f 5 starts early [65] and is the most frequently recognized dog allergen among 16-year-old subjects [66]. IgE-ab to Can $\mathrm{f} 5$ has been found in up to $70 \%$ of individuals sensitized to dog, among whom $38 \%$ were not sensitized to Can f 1, Can f 2, or Can f 3 [64]. Children who are mono-sensitized to Can f 5 are less likely to respond to a nasal provocation test compared to other dog dander-sensitized children [67] (Fig. 3).

The first case report has recently been published describing a dog-allergic patient who was mono-sensitized to Can $\mathrm{f} 5$ [60]. This individual did not show any reaction to either a SPT or an ocular provocation test using extracts derived from female dogs. These findings have been extended in a trial of 22 adolescents where 6 were truly mono-sensitized to Can $\mathrm{f} 5$; all 6 were positive to SPT using male dog extracts, whereas none was positive to a SPT using female dog extract [68]. The importance of dog gender has also been raised by Almqvist and colleagues [69], who used data from a population-based cohort to show that children who grew up with female dogs had a lower prevalence of asthma at age 6, than children who grew up with male dogs, speculating that excretion of and mono-sensitization to Can $f 5$ could explain this difference. Taken together these findings confirm that dog gender is of clinical importance and should be addressed in individuals mono-sensitized to Can $\mathrm{f} 5$.

\section{Allergy to Human Seminal Plasma - Cross-Reactivity with Can $\mathrm{f}$}

Human seminal plasma allergy covers a spectrum of clinical symptoms caused by local or systemic hypersensitivity reactions after contact with human ejaculate and was first described in 1958. Since then, $>100$ cases have been reported in medical literature [70]. However, the condition might be more frequent than expected. Recently, it was reported that $8 / 27$ Can $\mathrm{f} 5$-sensitized women reported allergic symptoms related to intercourse [71]. Symptoms usually occurred within $1 \mathrm{~h}$ of contact with seminal plasma although in a few cases symptoms were delayed. Most of the women with allergic reactions were between the ages of 20 and 40 years, and $>80 \%$ had a personal or family history of atopic conditions. In 2 separate

Highlighting the Usefulness of Molecular

Allergy in Clinical Practice studies of human seminal plasma, prostate-specific antigen has been identified as the causative allergen [72, 73], and in one of these studies, cross-reactivity between human prostate-specific antigen and dog-dander proteins was demonstrated [73].

Information concerning intimate behavior, and sex in general, as a trigger of allergic reactions is not abundant, probably due to the intimate nature of the problem. Nevertheless, reliable diagnostic procedures are available in some specific cases. The possible link between sexual activity and allergy should be logged in the case histories documented by allergists, in order to extend the diagnosis of unusual or unexplained conditions.

\section{Cannabis Allergy}

The attitude toward the use of cannabis is changing, and cannabis is now one of the most consumed drugs worldwide [74]. Although the drug is perceived as harmless, the increased use has rendered a greater awareness of the possible negative effect of cannabis, including the increased risk for asthma [75] and allergic reactions following cannabis consumption [76, 77]. Allergic reactions to cannabis can vary from mild rhinoconjunctivitis or urticaria to angioedema or severe systemic reactions [77, 78]. The majority of patients with severe and generalized symptoms are sensitized to Can s 3, a major allergen in Cannabis allergy classified as a nonspecific lipid transfer protein (nsLTP) which is found in Cannabis sativa [79]. Due to cross-reactivity, patients sensitized to Can s 3 are at risk of developing allergic reactions upon exposure to nsLTPs from other plant foods such as Pru p 3 (peach), Mal d 3 (apple), and Jug r 3 (walnut). Furthermore, the opposite may also occur, that is, patients sensitized to other nsLTPs can develop allergic symptoms upon exposure to cannabis [78], a pattern of cross-reactivity that is known as the cannabis-plant food syndrome [80]. Taken together, these findings suggest that analysis of IgE-ab to Can s 3 and other nsLTPs could be of importance in individuals with unexpected allergic reactions upon consumption of cannabis or plant foods such as peach, apple, and walnut. However, in the majority of studies on Cannabis allergy, a diagnosis is documented by skin prick test using buds or leaves which are difficult to standardize [78]. Decuyper et al. [78] propose that a highly sensitive diagnostic test, based on a crude extract (such as sIgE to hemp), should be used when there is clinical suspicion of allergy to cannabis. In the case of a negative result, cannabis allergy is highly unlikely. In the case of a positive

Int Arch Allergy Immunol 2021;182:904-916 
test result, however, they propose that the diagnostic workup should be complemented by validated component-based diagnostics (such as the BAT, sIgE, or SPT based on the Can $\mathrm{s} 3$ component) to further assess the risk for cannabis allergy. However, sIgE to Can s 3 is not commercially available at present.

\section{Conclusions}

Component-resolved diagnosis is rapidly being incorporated into clinical use, and allergists today are better able to estimate severity and prognosis for their allergic patients. This in turn leads to the improved safety and well-being of patients and their families. The use of allergen components paves the way for a more individual approach, or precision medicine when we investigate and care for patients with suspected allergic diseases. Molecular allergology is a powerful tool in the endeavor to explain allergic reactions, and we have only just begun our journey in understanding how various components are linked. The increasing availability of component-resolved diagnosis is further refining the diagnosis of IgE-mediated allergy. The patient remains in focus for us as allergists in the same way as the patient did when IgE was discovered. Today, we can better understand why patients react in an unexpected way, as illustrated by these examples, but there are many other clinical observations that remain to be unraveled. The emerging functions of IgE-ab in allergic diseases are still in focus, half a siècle after its discovery [81].

\section{Conflict of Interest Statement}

M.B. is an employee of Thermo Fisher Scientific. J.K. has received material from Thermo Fisher Scientific to perform IgE analyses in research projects not related to the current project. C.N. has no conflicts of interest to declare.

\section{Funding Sources}

J.K. is funded by a scholarship from Stockholm County Council to perform clinical research. The scholarship covered salary costs for the time J.K. worked on this project. C.N. and M.B. have no relevant funding sources to report.

\section{Author Contributions}

All the authors participated in conception of this work, critically reviewed data, were involved in manuscript writing and revision, and approved the last version of the manuscript before submission.

\section{References}

1 Johansson SGO. The discovery of IgE. J Allergy Clin Immunol. 2016;137(6):1671-3.

2 Johansson SG. Raised levels of a new immunoglobulin class (IgND) in asthma. Lancet. 1967;2(7523):951-3.

3 Valenta R, Lidholm J, Niederberger V, Hayek B, Kraft D, Grönlund H. The recombinant allergen-based concept of component-resolved diagnostics and immunotherapy (CRD and CRIT). Clin Exp Allergy. 1999;29(7):896-904.

4 Borres MP, Ebisawa M, Eigenmann PA. Use of allergen components begins a new era in pediatric allergology. Pediatr Allergy Immunol. 2011;22(5):454-61.

5 Rehm CD, Peñalvo JL, Afshin A, Mozaffarian D. Dietary intake among US adults, 19992012. JAMA. 2016;315(23):2542-53.

6 Garcia-Boyano M, Pedrosa M, Quirce S, Boyano-Martinez T. Household almond and peanut consumption is related to the development of sensitization in young children. J Allergy Clin Immunol. 2016;137(4):1248-51.e6.

7 Nilsson C, Berthold M, Mascialino B, Orme ME, Sjölander S, Hamilton RG. Accuracy of component-resolved diagnostics in peanut allergy: systematic literature review and metaanalysis. Pediatr Allergy Immunol. 2020; 31(3):303-14.
8 Tedner SG, Söderhäll C, Konradsen JR, Bains $\mathrm{K}$, Borres MP, Carlsen K-H, et al. Extract and molecular-based early infant sensitisation and associated factors: a PreventADALL study. Allergy. 2021. Accepted for publication.

9 Datema MR, Zuidmeer-Jongejan L, Asero R, Barreales L, Belohlavkova S, de Blay F, et al. Hazelnut allergy across Europe dissected molecularly: a EuroPrevall outpatient clinic survey. J Allergy Clin Immunol. 2015;136(2):382-91.

10 Uotila R, Kukkonen AK, Pelkonen AS, Mäkelä MJ. Cross-sensitization profiles of edible nuts in a birch-endemic area. Allergy. 2016;71(4):514-21.

11 Nilsson C, Berthold M, Mascialino B, Orme M, Sjölander S, Hamilton R. Allergen components in diagnosing childhood hazelnut allergy: systematic literature review and metaanalysis. Pediatr Allergy Immunol. 2020; 31(2):186-96

12 Masthoff LJ, Mattsson L, Zuidmeer-Jongejan L, Lidholm J, Andersson K, Akkerdaas JH, et al. Sensitization to Cor a 9 and Cor a 14 is highly specific for a hazelnut allergy with objective symptoms in Dutch children and adults. J Allergy Clin Immunol. 2013;132(2):393-9.

13 McWilliam V, Koplin J, Lodge C, Tang M, Dharmage S, Allen K. The prevalence of tree nut allergy: a systematic review. Curr Allergy Asthma Rep. 2015;15(9):54.

14 Elizur A, Appel MY, Nachshon L, Levy MB, Epstein-Rigbi N, Pontoppidan B, et al. Clinical and molecular characterization of walnut and pecan allergy (NUT CRACKER Study). J Allergy Clin Immunol Pract. 2020;8(1):157-65.e2.

15 Wangorsch A, Jamin A, Lidholm J, Gräni N, Lang C, Ballmer-Weber B, et al. Identification and implication of an allergenic PR-10 protein from walnut in birch pollen associated walnut allergy. Mol Nutr Food Res. 2017; 61(4).

16 Sato S, Yamamoto M, Yanagida N, Ito K, Ohya $Y$, Imai $T$, et al. Jug $r 1$ sensitization is important in walnut-allergic children and youth. J Allergy Clin Immunol Pract. 2017; 5(6):1784-6.e1.

17 Worm M, Moneret-Vautrin A, Scherer K, Lang R, Fernandez-Rivas M, Cardona V, et al. First European data from the network of severe allergic reactions (NORA). Allergy. 2014; 69(10):1397-404.

18 Johnson J, Malinovschi A, Alving K, Lidholm J, Borres MP, Nordvall L. Ten-year review reveals changing trends and severity of allergic reactions to nuts and other foods. Acta Paediatr. 2014;103(8):862-7. 
19 Vetander M, Helander D, Flodström C, Ostblom E, Alfvén T, Ly DH, et al. Anaphylaxis and reactions to foods in children: a population-based case study of emergency department visits. Clin Exp Allergy. 2012;42(4): 568-77.

20 Lange L, Lasota L, Finger A, Vlajnic D, Büsing $\mathrm{S}$, Meister J, et al. Ana o 3-specific IgE is a good predictor for clinically relevant cashew allergy in children. Allergy. 2017;72(4):598603.

21 Noorbakhsh R, Mortazavi SA, Sankian M, Shahidi F, Tehrani M, Azad FJ, et al. Pistachio allergy-prevalence and in vitro cross-reactivity with other nuts. Allergol Int. 2011;60(4): $425-32$.

22 Savvatianos S, Konstantinopoulos AP, Borgå $\AA$, Stavroulakis G, Lidholm J, Borres MP, et al. Sensitization to cashew nut $2 \mathrm{~S}$ albumin, Ana o 3 , is highly predictive of cashew and pistachio allergy in Greek children. J Allergy Clin Immunol. 2015;136(1):192-4.

23 Too JJY, Shek LP, Rajakulendran M. Crossreactivity of pink peppercorn in cashew and pistachio allergic individuals. Asia Pac Allergy. 2019;9(3):e25.

24 Blazowski L, Majak P, Kurzawa R, Kuna P, Jerzynska J. Food allergy endotype with high risk of severe anaphylaxis in children-monosensitization to cashew $2 \mathrm{~S}$ albumin Ana o 3 . Allergy. 2019;74(10):1945-55.

25 Andorf S, Borres MP, Block W, Tupa D, Bollyky JB, Sampath V, et al. Association of clinical reactivity with sensitization to allergen components in multifood-allergic children. J Allergy Clin Immunol Pract. 2017;5(5):132534.e4.

26 O'Sullivan MD, Somerville C. Cosensitization to orange seed and cashew nut. Ann Allergy Asthma Immunol. 2011;107(3):282-3.

27 Turner PJ, Gray PE, Wong M, Varese N, Rolland JM, O’Hehir R, et al. Anaphylaxis to apple and orange seed. J Allergy Clin Immunol. 2011;128(6):1363-5.

28 Brandstrom J, Lilja G, Nilsson C, Ingemarsson $\mathrm{N}$, Borres MP, Brostedt P, et al. IgE to novel citrus seed allergens among cashew-allergic children. Pediatr Allergy Immunol. 2016;27(5):550-3.

29 Glaspole IN, de Leon MP, Rolland JM, O'Hehir RE. Anaphylaxis to lemon soap: citrus seed and peanut allergen cross-reactivity. Ann Allergy Asthma Immunol. 2007;98(3): 286-9.

30 van Zuuren EJ, Terreehorst I, Tupker RA, Hiemstra PS, Akkerdaas JH. Anaphylaxis after consuming soy products in patients with birch pollinosis. Allergy. 2010;65(10):1348-9.

31 Kosma P, Sjölander S, Landgren E, Borres MP, Hedlin G. Severe reactions after the intake of soy drink in birch pollen-allergic children sensitized to Gly m 4. Acta Paediatr. 2011;100(2):305-6.

32 Kleine-Tebbe J, Vogel L, Crowell DN, Haustein UF, Vieths S. Severe oral allergy syndrome and anaphylactic reactions caused by a Bet $\mathrm{v}$ 1-related PR-10 protein in soybean,
SAM22. J Allergy Clin Immunol. 2002;110(5): 797-804.

33 Mittag D, Vieths S, Vogel L, Becker WM, Rihs HP, Helbling A, et al. Soybean allergy in patients allergic to birch pollen: clinical investigation and molecular characterization of allergens. J Allergy Clin Immunol. 2004;113(1): $148-54$.

34 Fukutomi Y, Sjölander S, Nakazawa T, Borres MP, Ishii T, Nakayama $S$, et al. Clinical relevance of IgE to recombinant Gly $\mathrm{m} 4$ in the diagnosis of adult soybean allergy. J Allergy Clin Immunol. 2012;129(3):860-3.e3.

35 Makinen OE, Wanhalinna V, Zannini E, Arendt EK. Foods for special dietary needs: non-dairy plant-based milk substitutes and fermented dairy-type products. Crit Rev Food Sci Nutr. 2016;56(3):339-49.

36 Storhaug CL, Fosse SK, Fadnes LT. Country, regional, and global estimates for lactose malabsorption in adults: a systematic review and meta-analysis. Lancet Gastroenterol Hepatol. 2017;2(10):738-46.

37 McClements DJ, Newman E, McClements IF. Plant-based milks: a review of the science underpinning their design, fabrication, and performance. Compr Rev Food Sci Food Saf. 2019;18(6):2047-67.

38 Patel K, Vila-Nadal G, Shah J, Shamji MH, Swan L, Durham SR, et al. Is pollen-food syndrome a frequent comorbidity in adults with irritable bowel syndrome? Allergy. 2020; 75(7):1780-3.

39 Rentzos G, Lundberg V, Stotzer PO, Pullerits $\mathrm{T}$, Telemo E. Intestinal allergic inflammation in birch pollen allergic patients in relation to pollen season, IgE sensitization profile and gastrointestinal symptoms. Clin Transl Allergy. 2014;4:19.

40 Klingebiel C, Chantran Y, Arif-Lusson R, Ehrenberg AE, Östling J, Poisson A, et al. Pru $\mathrm{p}$ 7 sensitization is a predominant cause of severe, cypress pollen-associated peach allergy. Clin Exp Allergy. 2019;49(4):526-36.

41 Ando Y, Miyamoto M, Kato M, Nakayama M, Fukuda H, Yoshihara S. Pru p 7 predicts severe reactions after ingestion of peach in Japanese children and adolescents. Int Arch Allergy Immunol. 2020;181(3):183-90.

42 Skypala IJ. Can patients with oral allergy syndrome be at risk of anaphylaxis? Curr Opin Allergy Clin Immunol. 2020;20(5):459-64.

43 Matricardi PM, Kleine-Tebbe J, Hoffmann HJ, Valenta R, Hilger C, Hofmaier S, et al. EAACI molecular allergology user's guide. Pediatr Allergy Immunol. 2016;27(Suppl 23): $1-250$.

44 Wilson JM, Platts-Mills TAE. Red meat allergy in children and adults. Curr Opin Allergy Clin Immunol. 2019;19(3):229-35.

45 Martelli A, De Chiara A, Corvo M, Restani P, Fiocchi A. Beef allergy in children with cow's milk allergy; cow's milk allergy in children with beef allergy. Ann Allergy Asthma Immunol. 2002;89(6 Suppl 1):38-43.

46 Apostolovic D, Mihailovic J, Commins SP, Wijnveld M, Kazimirova M, Starkhammar M, et al. Allergenomics of the tick Ixodes ricinus reveals important $\alpha$-Gal-carrying IgE-binding proteins in red meat allergy. Allergy. 2020; 75(1):217-20.

47 Hamsten C, Tran TAT, Starkhammar M, Brauner A, Commins SP, Platts-Mills TAE, et al. Red meat allergy in Sweden: association with tick sensitization and B-negative blood groups. J Allergy Clin Immunol. 2013;132(6): 1431-4.

48 Commins SP, Satinover SM, Hosen J, Mozena J, Borish L, Lewis BD, et al. Delayed anaphylaxis, angioedema, or urticaria after consumption of red meat in patients with IgE antibodies specific for galactose-alpha-1,3-galactose. J Allergy Clin Immunol. 2009;123(2):426-33.

49 Kiewiet MG, Grundstrom J, Apostolovic D, Andersson M, Borres MP, Hamsten C, et al. Elucidating the alpha-gal syndrome at the molecular allergen level. Allergy. 2020.

50 Hemmer W, Klug C, Swoboda I. Update on the bird-egg syndrome and genuine poultry meat allergy. Allergo J Int. 2016;25:68-75.

51 Ballardini N, Nopp A, Hamsten C, Vetander M, Melén E, Nilsson C, et al. Anaphylactic reactions to novel foods: case report of a child with severe crocodile meat allergy. Pediatrics. 2017;139(4):e20161404.

52 Green RE, Braun EL, Armstrong J, Earl D, Nguyen N, Hickey G, et al. Three crocodilian genomes reveal ancestral patterns of evolution among archosaurs. Science. 2014; 346(6215): 1254449.

53 Kuehn A, Codreanu-Morel F, Lehners-Weber C, Doyen V, Gomez-André SA, Bienvenu $\mathrm{F}$, et al. Cross-reactivity to fish and chicken meat: a new clinical syndrome. Allergy. 2016; 71(12):1772-81.

54 Available from: https://www.persistencemarketresearch.com/market-research/edible-insects-market.asp.

55 Broekman HCHP, Knulst AC, de Jong G, Gaspari M, den Hartog Jager CF, Houben GF, et al. Is mealworm or shrimp allergy indicative for food allergy to insects? Mol Nutr Food Res. 2017;61(9).

56 Kamemura N, Sugimoto M, Tamehiro N, Adachi R, Tomonari S, Watanabe $\mathrm{T}$, et al. Cross-allergenicity of crustacean and the edible insect Gryllus bimaculatus in patients with shrimp allergy. Mol Immunol. 2019;106: $127-34$.

57 Malinovschi A. Prevalence of sensitization to shrimp and mite in a Swedish adult population: data from the SCAPIS-study. In: Borres M, editor. 2020.

58 Skypala IJ. Food-induced anaphylaxis: role of hidden allergens and cofactors. Front Immunol. 2019; 10:673.

59 Canavan M, Mitchell A, Sharkey A, Whitethorn C, McNicholl B, Robinson S, et al. Oral mite anaphylaxis. QJM. 2018;111(3):189-90.

60 Schoos AM, Bønnelykke K, Chawes BL, Stokholm J, Bisgaard H, Kristensen B. Precision allergy: separate allergies to male and female dogs. J Allergy Clin Immunol Pract. 2017; $5(6): 1754-6$. 
61 Konradsen JR, Fujisawa T, van Hage M, Hedlin G, Hilger C, Kleine-Tebbe J, et al. Allergy to furry animals: new insights, diagnostic approaches, and challenges. J Allergy Clin Immunol. 2015;135(3):616-25.

62 Schoos AM, Nwaru BI, Borres MP. Component-resolved diagnostics in pet allergy: current perspectives and future directions. $\mathrm{J} \mathrm{Al}$ lergy Clin Immunol. 2021;147(4):1164-73.

63 Sub-Committee WIAN. Allergen nomenclature 2021 [updated $2021 \mathrm{Feb}$ 15]. Available from: www.allergen.org.

64 Mattsson L, Lundgren T, Everberg H, Larsson $\mathrm{H}$, Lidholm J. Prostatic kallikrein: a new major dog allergen. J Allergy Clin Immunol. 2009; 123(2):362-8.

65 Nagao M, Borres MP, Sugimoto M, Petersson CJ, Nakayama S, Kuwabara Y, et al. Sensitization to secretoglobin and lipocalins in a group of young children with risk of developing respiratory allergy. Clin Mol Allergy. 2017;15:4.

66 Asarnoj A, Hamsten C, Waden K, Lupinek C, Andersson N, Kull I, et al. Sensitization to cat and dog allergen molecules in childhood and prediction of symptoms of cat and dog allergy in adolescence: a BAMSE/MeDALL study. J Allergy Clin Immunol. 2016;137(3):813-21. e7.

67 Kack U, Asarnoj A, Gronlund H, Borres MP, van Hage M, Lilja G, et al. Molecular allergy diagnostics refine characterization of children sensitized to dog dander. J Allergy Clin Immunol. 2018;142(4):1113-20.e9.
68 Schoos AM, Chawes BL, Bloch J, Hansen B, Stokholm J, Bønnelykke K, et al. Children monosensitized to Can $\mathrm{f} 5$ show different reactions to male and female dog allergen extract provocation: a randomized controlled trial. J Allergy Clin Immunol Pract. 2020;8(5): 1592-7.e2.

69 Fall T, Ekberg S, Lundholm C, Fang F, Almqvist C. Dog characteristics and future risk of asthma in children growing up with dogs. Sci Rep. 2018;8(1):16899.

70 Weidinger S, Ring J, Köhn FM. IgE-mediated allergy against human seminal plasma. Chem Immunol Allergy. 2005;88:128-38.

71 Gonzalez-de-Olano D, Gandolfo-Cano M, de-Calzada-Bustingorri MP, GonzalezMancebo E, de-Andres-Martin A, CuestaHerranz J, et al. Prevalence of allergy to human seminal fluid among women with allergy to male dog and sensitization to Can $\mathrm{f} 5$. Clin Exp Allergy. 2018;48(10):1368-70.

72 Weidinger S, Mayerhofer A, Raemsch R, Ring J, Köhn FM. Prostate-specific antigen as allergen in human seminal plasma allergy. J Allergy Clin Immunol. 2006;117(1):213-5.

73 Basagana M, Bartolome B, Pastor C, Torres F, Alonso R, Vivanco F, et al. Allergy to human seminal fluid: cross-reactivity with dog dander. J Allergy Clin Immunol. 2008;121(1): 233-9.

74 United Nations Office on Drugs and Crime. World drug report. 2017. Available from: www.unodc.org/wdr2017.
75 Bramness JG, von Soest T. A longitudinal study of cannabis use increasing the use of asthma medication in young Norwegian adults. BMC Pulm Med. 2019;19(1):52.

76 Golick J. Shifting the paradigm: adolescent cannabis abuse and the need for early intervention. J Psychoactive Drugs. 2016;48(1): 24-7.

77 Alkhammash S, Tsui H, Thomson DMP. Cannabis and hemp seed allergy. J Allergy Clin Immunol Pract. 2019 Sep-Oct;7(7): 2429-30.e1.

78 Decuyper II, Van Gasse AL, Faber MA, Elst J, Mertens C, Rihs HP, et al. Exploring the diagnosis and profile of cannabis allergy. J Allergy Clin Immunol Pract. 2019;7(3):983-9.e5.

79 Gamboa P, Sanchez-Monge R, Sanz ML, Palacín A, Salcedo G, Diaz-Perales A. Sensitization to cannabis sativa caused by a novel allergenic lipid transfer protein, Can s 3. J Allergy Clin Immunol. 2007;120(6):1459-60.

80 Ebo DG, Swerts S, Sabato V, Hagendorens $\mathrm{MM}$, Bridts $\mathrm{CH}$, Jorens $\mathrm{PG}$, et al. New food allergies in a European non-mediterranean region: is cannabis sativa to blame? Int Arch Allergy Immunol. 2013;161(3):220-8.

81 Oettgen HC. Fifty years later: emerging functions of IgE antibodies in host defense, immune regulation, and allergic diseases. $\mathrm{J} \mathrm{Al}$ lergy Clin Immunol. 2016;137(6):1631-45. 